\title{
Effectiveness of the Hearing Handicap Inventory for Elderly (HHIE) in Measuring the Current State of Presbycusis
}

\author{
Seung-Deok Heo \\ Department of Speech-Language Pathology, College of Rehabilitation Science, Daegu University, Gyeongsan, Korea
}

Correspondence: Seung-Deok Heo, PhD Department of Speech-Language Pathology, College of Rehabilitation Science, Daegu University, 201 Daegudae-ro, Jillyang-eup, Gyeongsan 38453, Korea Tel: $+82-53-850-4326$

Fax: $+82-53-850-4329$

E-mail: audiolog@daegu.ac.kr

Received: December 14, 2016

Revised: February 1, 2017

Accepted: February 3, 2017

\begin{abstract}
Objectives: The goal of this study is to discern the effects of age-related hearing loss using the Hearing Handicap Inventory for Elderly (HHIE) via a smartphone platform with elderly individuals who are urban residents. Methods: Ninety-two elderly 65 years of age or older participated in this study, divided into groups by age. Group 1 subjects were 65 to 69 years, group 2 subjects were 70 to 79 years, and group 3 were 80 years or older. The questionnaire surveyed 82 participants excluding 10 amplifier users; 79 participants completed the questionnaire. The internal consistency marker was Cronbach's alpha coefficient $(\alpha=.918)$, and the criterion for suspected hearing loss criteria was 18 points or more. The status of presbycusis was analyzed in 89 subjects who were amplified users and completed questionnaires (one-way ANOVA, Pearson correlation analysis). Results: The rate of suspected hearing loss confirmed by HHIE was $16.7 \%$ in group $1,25.5 \%$ in group 2 , and $45 \%$ in group 3, respectively. The rate increased with age significantly $(r=.392, p=.01)$. The status of presbycusis including amplifier users was $22.2 \%, 37.3 \%$, and $60 \%$ in the same order. The status of presbycusis also increased with age significantly $(r=.319, p=.01)$. Conclusion: Presbycusis increases rapidly with age, and HHIE can be a useful tool for hearing screening of the elderly.
\end{abstract}

Keywords: Presbycusis, Aging, Hearing, HHI, Hearing Handicap Inventory, HHIE
청력손실은 청각기관 손상으로 인한 듣기 능력 손실을 의미하 며, 말초 및 중추 청각기관의 퇴행, 음성언어를 이용한 의사소통 지 장, 사회적 관계 형성 등 개인의 전반적 영역에서 문제를 동반한다.

노인성 난청(presbycusis, age-related hearing loss)은 신체 기능 의 노화에 의해 생기며, 30 대 이후부터 시작하여 청력손실을 자각 하는 시기는 개인마다 다르다. 노인성 난청은 일반적으로 청력손실 이 양측 대칭성으로 고주파수 대역 가청역치부터 나빠져서 어음주 파수 영역으로 침범한다. 또한 노화가 원인인 청력손실은 청각처리 와 관련하여 어음이해도도 낮아지고(음소회귀) (Martin \& Clark, 2015), 베타아밀로이드(beta amyloid)가 베르니케 영역에 축적되어 회복 불가능한 인지장애 및 치매로 발전할 수 있어서 심각하다(Lin et al., 2011). 실제로 연령이 높아지면서 치매 유병률도 높아지며 (Woo et al., 1997), 이외에도 이명이 동반되기도 하며, 정서 심리적
문제를 야기하기도 한다.

노인성 난청의 원인에는 감각성, 신경성, 대사성(혈관조), 와우 운 동성(와우 전음성) 등이 있다(Schmiedt, 2010; Schuknecht, 1993). 감각성은 유모세포와 지지세포의 손상이, 신경성은 구심성 청신경 섬유의 손상이 원인이다. 대사성은 와우 외벽과 혈관조 위축에 의 한 내림프 성상 변화가, 와우 운동성은 기저막의 유리질화와 코르 티 기관의 강직(긴장)이 원인이다. 이들 손상은 대체로 기저회전에 서 심하여 고음역 손실이 크고 진행하면서 어음역으로 파급된다. 이외에도 유전과 고혈압 및 혈관 질환, 소음, 약물, 흡연, 음주 등에 의한 환경적 요인들이 복합적으로 관여한다.

우리나라의 난청 진료 인원은 2013년 기준 28만 1천 명으로 2008 년 22만 2천 명에 비해 $26.7 \%$ 증가하였고, 이들의 $44.5 \%$ 가 60 대 이 상이다(Korea Ministry of Health and Welfare, 2014). 난청자의 청 
각장애 등록은 순음청력손실 평균(pure tone average, PTAs)이 양 측 $60 \mathrm{~dB} \mathrm{HL}$ 이상 대칭성이거나 두 귀 각각이 40 과 $80 \mathrm{~dB} \mathrm{HL}$ 이상 또는 심한 이명이 있는 40 과 $80 \mathrm{~dB} \mathrm{HL}$ 이상 비대칭성일 때이며, 이 상의 기준에 포함되어 청각장애를 등록한 전체 인원은 25,000 명 정 도이다(Korean Statistical Information Service, 2016). 장애등급은 $500,1,000,2,000,4,000 \mathrm{~Hz}$ 기도 가청역치를 이용하고, 1,000 과 2,000 $\mathrm{Hz}$ 를 가중하는 $6 \mathrm{PTAs}$ 로 결정한다. 그러나 노인성 난청은 고음역 의 손실이 커서 청력손실을 자각하고 실지로 불편을 느끼는 경우 가 등록한 인원보다 현저하게 많을 것으로 추정되지만 우리나라는 저소득 신생아에게만 국가적 차원의 청각선별을 시행하고 있다 (Heo, 2015, 2016; Oh \& Heo, 2016).

노인성 난청은 적절한 청각언어재활서비스를 제공하면 개인적 성취와 사회 참여 및 통합을 기대(Kim \& Yeo, 2015)할 수 있으나 진 행이 매우 느려서 자각하기 어렵기 때문에 청각선별을 통한 조기 발견이 중요하다. 청각선별, 난청 진단 및 재활서비스는 유기적으로 제공하지 않으면 난청자 개인의 건강과 사회 참여의 제한으로 삶의 질이 낮아지고, 가정 경제를 어렵게 만들며(Kang \& Yoon, 2013), 인 지 기능 손실(Lin et al., 2011)로 이어질 수 있다.

우리나라 스마트폰 보급률은 $91 \%$ 에 이르며(Park, 2016), 50대 이 상의 이용률은 다른 연령대 대비 상대적으로 큰 폭으로 증가하였 다(Korea Internet \& Security Agency, 2015). 애플리케이션은 스마 트폰의 활용도를 높일 수 있는 소프트웨어이다.

우리나라에서 스마트폰 애플리케이션 기반 청각선별은 순음청 각선별이 있으나 아직 널리 사용되지 않고 있으며(Project Team for Audiology Study Group, 2014, 2015), 설문을 이용하는 청각선별검 사(Hearing Handicap Inventory for Elderly, HHIE)도 타당도가 검증되었으나 $(\mathrm{Ku} \& \mathrm{Kim}, 2000)$ 마찬가지로 널리 사용되지 못하고 있다. 하지만 이 도구들은 사용이 간단하면서도 효용성이 높아 스 마트폰 애플리케이션으로 충분히 활용할 수 있다(Heo, Park, \& Song, 2017). 따라서 인프라가 충분한 스마트폰과 애플리케이션을 이용한 청각선별은 친숙한 사용자 환경에서 개인이 적극적으로 청 각선별을 시행할 수 있을 것으로 기대할 수 있다.

이 연구는 체계적인 청각선별이 이루어지지 않고 있는 노인을 대 상으로 애플리케이션 기반 HHIE을 시행하여 노인성 난청 실태를 추정해 보고자한다.

\section{연구 방법}

\section{연구 대상}

연구 참여자들은 연구 목적을 충분히 이해하였고, 결과 활용에
동의하였다.

참여자들은 경산, 목포, 통영시 행정구역 내 도농 및 주거, 상업지 역에 거주하는 65 세 이상(75.03 \pm 6.205$)$ 성인 92명(남 17, 여 75)이 었다. 참여자들은 주간 활동으로 종교단체, 노인정, 복지시설 등을 방문하고 있었고, 설문 조사연구는 이들 기관에서 시행하였다.

증폭기 사용자는 인공와우 이식자가 1 명(bimodal), 보청기 사용 자가 9 명으로 모두 10 명이었다.

$\mathrm{HHIE}$ 는 증폭기 사용자 10 명을 제외한 82 명이 응답하였고, 응답 점수는 하나또는 두 개의 문항에서 응답이 없었던 3 명을 제외하였다.

분석 대상은 난청 실태 추정을 위하여 HHIE 유효 응답자 79명 과 난청을 확진 받고 증폭기를 사용하고 있었던 10 명 등을 포함한 89명으로 하였다. 이들은 연령에 따라 65-69세를 1군으로, 70-79세 를 2군으로, 80 세 이상(91세 1명 포함)을 3군으로 각각 나누었다. 이 들은 모두 89 명으로 1 군의 경우 $\mathrm{HHIE}$ 응답자가 17 명, 증폭기 사용 자가 1 명으로 모두 18 명이었고, 같은 순서로 2 군의 경우 45 명, 6 명으 로 모두 51 명, 3 군의 경우 17 명, 3 명으로 모두 20 명이었다.

\section{연구 방법}

$\mathrm{HHIE}$ 문항은 25개로 구성되어 있고, 내용은 Appendix 1과 같다. 문항에 대한 응답은 '그렇지 않다(0점)', '때때로 그렇다(2점)', '항 상 그렇다(4점)' 중 하나를 선택하게 하였다. 응답의 내적 일관성은 Cronbach's alpha coefficient로 검증하였으며, 검증 결과 Cronbach's $\alpha$ 는 .918 로 관찰되었다.

설문은 참여자가 개인용 스마트폰으로 설문조사 사이트에 접근 하여 응답하게 하였다. 이 과정에서 필요한 경우 연구자가 참여자 의 사이트 접근에 필요한 도움을 제공하였고, 스마트폰이 없거나 스마트폰 사용이 서툰 경우 연구자가 면접으로 진행하면서 스마트 폰에 결과를 입력하였다.

면접 과정에서 청력손실을 확진 받고 인공와우나 보청기 등 증폭 기 사용이 확인된 경우에는 설문조사 대신 증폭기 사용에 대한 재 활 상담을 시행하였다. 재활 상담 후, 결과 활용에 동의한 경우 연구 대상의 난청자로 추가하였다.

설문조사는 응답 점수가 100 점 중 18 점 이상이면 경도 이상의 난 청으로 의심한다(Ventry \& Weinstein, 1982). 이를 고려하여 이보 다 미만이면 정상 청력자, 이상이면 난청 유소견자로 각각 결정한 후, 난청 유소견자 비율을 백분율로 구하였다.

난청 실태는 증폭기 사용자와 HHIE 난청 유소견자를 합하여 백 분율로 구하였다. 집단별 차이는 일원배치 분산분석(one-way ANOVA)으로 검증하였다(SPSS Statistics ver. 22). 
Table 1. Mean score and standard deviations of HHIE in each group

\begin{tabular}{lccc}
\hline & $\begin{array}{c}\text { WNL (HHIE }<18) \\
(\mathrm{N}=54)\end{array}$ & $\begin{array}{c}\text { HL suspicious } \\
(\mathrm{HHIE} \geq 18)(\mathrm{N}=25)\end{array}$ & $\begin{array}{c}\text { Total } \\
(\mathrm{N}=79)\end{array}$ \\
\hline Group 1 $(\mathrm{N}=17)$ & $.76 \pm 1.921$ & $22.67 \pm 3.055$ & $4.588 \pm 8.85$ \\
Group 2 $(\mathrm{N}=45)$ & $2.38 \pm 4.294$ & $24.17 \pm 7.883$ & $8.578 \pm 11.21$ \\
Group 3 $(\mathrm{N}=17)$ & $6.25 \pm 6.798$ & $27.56 \pm 18.022$ & $17.529 \pm 17.40$ \\
Total $(\mathrm{N}=79)$ & - & - & $9.769 \pm 13.03$ \\
\hline
\end{tabular}

Values are presented as mean \pm SD.

$\mathrm{HHIE}=$ Hearing Handicap Inventory for Elderly; $\mathrm{WNL}=$ within normal limits; $\mathrm{HL}=$ hearing loss.

\section{연구 결과}

$\mathrm{HHIE}$ 점수 평균은 1군이 $4.588 \pm 8.85$ 점, 2군이 $8.578 \pm 11.21$ 점, 3 군이 $17.529 \pm 17.4$ 점으로 각각 관찰되었고, 1 군과 3 군 $(p=.01), 2$ 군 과 3 군 $(p=.04)$ 사이에서 유의한 차이가 나타났다(Table 1).

$\mathrm{HHIE} 18$ 점 미만인 정상 평균은 1군 .76 \pm 1.921 점, 2군 $2.38 \pm$ 4.294점, 3군 $6.25 \pm 6.798$ 점으로, 집단 간 유의한 차이가 관찰되었 다 $(F=4.038, p=.006)$. HHIE 18 점 이상인 난청 유소견자 평균은 1 군 $22.67 \pm 3.055$ 점, 2 군 $24.17 \pm 7.883$ 점, 3군 $27.56 \pm 18.022$ 점으로 집단 간 유의한 차이가 관찰되었고 $(F=2.693, p=.003)$ 나이가 들 수록 유의하게 높아졌다 $(r=.392, p=.01)$ (Table 1).

$\mathrm{HHIE}$ 에 의한 난청 유소견자 비율은 1 군 $16.7 \%, 2$ 군 $25.5 \%, 3$ 군 $45 \%$ 로, 집단 간 유의한 차이가 있었다 $(p=.003)$. 증폭기 사용자를 포함한 난청 실태는 1 군 $22.2 \%, 2$ 군 $37.3 \%, 3$ 군 $60 \%$ 로 집단 간 유의 한 차이가 관찰되었고 $(p=.004)$ 나이가 들수록 유의하게 높아졌다 $(r=.319, p=.01)$ (Table 2).

\section{논의 및 결론}

청력손실은 특히 고령 인구 삶의 질에 심각한 영향을 줄 수 있으 나 청력손실이 고도 이상일지라도 인공와우를 이식하고 청각언어 재활서비스를 제공하면 노인의 언어 인지 및 삶의 질에 긍정적 영 향이 있다(Lee, 2011). 청각언어재활 서비스 제공을 위해서는 난청 의 조기 발견이 중요하며, 조기 발견을 위해서는 적극적인 청력검사 가 필요하다. 하지만 고령자들은 거동에 어려움이 있어서 서비스 제공자가 방문하거나 가족 구성원의 도움을 받는다면 효과를 더욱 높일 수 있다. 스마트폰 기반의 설문도 사용자 중심으로 청각선별 의 실효성을 높이는데 도움을 줄 수 있으며, 이들 도구는 무엇보다 타당도와 신뢰도 등에서 믿을 수 있어야 한다.

외국의 경우 멕시코계 미국인을 대상으로 한 영어와 스페인어 단축형 $\mathrm{HHIE}$ 점수가 $6.2 \pm 8.7$ 와 $6.2 \pm 9.3$ 로 높은 상관관계 $(r=.89)$
Table 2. Status of presbycusis using HHIE

\begin{tabular}{lccr}
\hline & HL suspicious & Amplifier user & HL status \\
\hline Group 1 $(\mathrm{N}=18)$ & $3(16.7)$ & $1(5.6)$ & $4(22.2)$ \\
Group 2 $(\mathrm{N}=51)$ & $13(25.5)$ & $6(11.8)$ & $19(37.3)$ \\
Group 3 $(\mathrm{N}=20)$ & $9(45.0)$ & $3(15.0)$ & $12(60.0)$ \\
Total $(\mathrm{N}=89)$ & $25(28.1)$ & $10(11.2)$ & $35(39.3)$ \\
\hline
\end{tabular}

Values are presented as number (\%).

$\mathrm{HHIE}=$ Hearing Handicap Inventory for Elderly; $\mathrm{HL}=$ hearing loss .

가 있는 것으로 관찰되었고(Lichtenstein \& Hazuda, 1998), 이집트 인에서 단축형 HHIE 점수가 순음청력검사 결과와 높은 타당도 (Cronbach's alpha =.902)로 유의한 관계 $(r=.688, p=.000)$ 가 있는 것으로 확인되었다(Weinstein, Rasheedy, Taha, \& Fatouh, 2015). 스웨덴에서도 HHIE와 단축형 HHIE 점수가 보청기 사용시 22.0 \pm 8.1 점과 $14 \pm 4.2$ 점, 그렇지 않았을 때 $20.4 \pm$ 7.3점과 $13.1 \pm 3.6$ 점 으로, 청각언어재활서비스 제공 전 $21.5 \pm 8.4$ 점과 $13.4 \pm 4.2$ 점, 제 공 후 $9.9 \pm 7.9$ 점과 $6.4 \pm 5.0$ 점으로 각각 보고하면서 보청기 재활 평가 과정에서도 유용한 것으로 보고하였다(Öberg, 2016). HHIE 는 이외에도 나이지리아어(Sogebi \& Mabifah, 2015), 브라질어(Aiello, de Lima, \& Ferrari, 2011), 이집트어(Weinstein et al., 2015), 이 탈리아어(Monzani et al., 2007), 인도어(Deepthi \& Kasthuri, 2012), 일본어(Tomioka et al., 2013), 중국어(Liu, Han, \& Yang, 2016), 포르 투칼어(de Paiva et al., 2016) 등 다양한 문화권 국가에서 언어가 달 라지더라도 타당도가 높고 신뢰도가 있는 도구로 확인되었다. 우리 말 설문형 자가 응답 청각선별 도구도 단축형 HHIE는 9.29 13.32 점(Ku \& Kim, 2000)으로 민감도와특이도가 높은 것으로 나타났고, 이 연구에서도 Cronbach's alpha가 .918로 관찰되어 여러 선행연구 결과와 일관된 경향을 보였다. 아울러 $\mathrm{HHIE}$ 는 어음역 및 고음역 PTA와 상관관계가 있는 것(Hong \& Lee, 2002)으로 보고되었다.

설문을 이용한 청각선별은 충분한 유병률로 선별할 수 있어야 한 다. 2016년 12월 현재, 우리나라 인구는 51,687천명이며, 이 중 65세 인구가 6,987명으로 전체 인구의 $13.49 \%$ 에 이르며, 나이가 들어가 면서 고령층 인구는 줄어들고 있다(Korea Ministry of the Interior, 2016). 그렇지만 기대 수명은 의학 발전 등의 영향으로 더욱 연장되 고 있다(Statistics Korea, 2016).

언어를 습득한 성인의 청력손실은 경도 이상이면 자각할 수 있고, 서비스 영역(serviceable range)을 초과하면 일상생활에 지장을 느 낄 수 있다. 2010-2012 국민건강영양조사에서 PTA가 $40 \mathrm{~dB} \mathrm{HL}$ 이 상으로 일상생활에 불편을 느낄 수 있는 난청 인구는 60 대가 $11.88 \%$, 70대가 $26.26 \%, 80$ 대 이상이 $52.83 \%$ 로 관찰되었다(Lee, 2016). 노 인성 난청 인구는 인구 구성 및 기대 수명 연장에 따른 생존 노인 인 
구 비율을 고려하면 증가가 당연하고, 고령일수록 더욱 높아진다. 이 연구의 HHIE는 65-69세 범위, 70대, 80세 이상에서 각각 4.59점, 8.58점, 17.53 점이었고, 이 점수는 국민건강영양조사와 달리 PTA상 경도 이상 $(26 \mathrm{~dB} \mathrm{HL})$ 난청을 의미한다. 이 연구를 통해 확인한 난 청 실태는 각각 $16.7 \%, 25.5 \%, 45 \%$ 로 국민건강영양조사보다 보수 적이기는 하지만 나이가 들어갈수록 빠르게 높아지는 점에서 비슷 한 경향을 보였다. 65 세 이상 인구의 난청자는 $36.8 \%$ 로 보고된 바 있으며(Ahn, Song, Park, Lee, \& Chae, 2010), 증폭기 사용자를 포 함한 이 연구의 유소견자 비율은 $39.3 \%$ 로 확인되었다. 또 80 세 이 상 유소견자 비율은 $45 \%$ 로 같은 해 시행된 선행연구의 $42.9 \%(\mathrm{Liu}$ et al., 2016)와 비슷한 수준이다.

노인성 난청이 의사소통 문제와 청각박탈에 의한 청신경 퇴행, 인지 및 정서적 문제 등을 유발시킬 수 있다는 점을 고려하면 이에 대한 대책은 시급하다. 청력손실은 삶의 질에 부정적인 영향을 미 치며, 청각선별은 이러한 부정적 영향을 예방하는 데 기여할 수 있 다. 체계적인 청각선별은 많은 예산과 시간이 필요하기 때문에 국가 적 노력이 필요하다. HHIE는 스마트폰 애플리케이션 기반으로 활 용할 수 있어서 적은 비용과 노력으로 상당한 효과를 얻을 수 있을 것으로 기대된다. 아울러 이 연구에서 사용한 도구는 경쟁 잡음 환 경에서 이해에 관한 문항이 포함되어 있어서 중추 기능 이상을 선 별하는데도 유용하다(Pratt, 2016).

결론적으로 이 연구에서 확인한 65세 이상 도농지역 고령 인구 의 난청 실태는 60 대, 70 대, 80 세 이상 세대에서 각각 $22.2 \%, 37.2 \%$, $60 \%$ 로 관찰되었고, 난청 유소견자 비율은 나이가 들어갈수록 급 격하게 높아졌다. 이 결과는 이미 확인된 난청 실태와 비슷한 양상 이다. 따라서 스마트폰 애플리케이션 기반 HHIE는 높은 노인성 난 청을 선별하는 도구로 유용하게 사용할 수 있을 것으로 기대된다.

\section{REFERENCES}

Ahn, J. H., Song, J. J., Park, M. K., Lee, J. H., \& Chae, S. W. (2010). Age related hearing loss in Korea: a healthcare center-based study. Journal of the Korean Geriatrics Society, 14, 258-264.

Aiello, C. P., de Lima, I. I., \& Ferrari, D. V. (2011). Validity and reliability of the hearing handicap inventory for adults. Brazilian Journal of Otorhinolaryngology, 77, 432-438.

de Paiva, S. M. M., Simões, J., Paiva, A., Newman, C., Castro e Sousa, F., \& Bébéar, J. P. (2016). Validity and reliability of the Hearing Handicap Inventory for Elderly: version adapted for use on the Portuguese population. Journal of the American Academy of Audiology, 27, 677-682.
Deepthi, R., \& Kasthuri, A. (2012). Validation of the use of self-reported hearing loss and the Hearing Handicap Inventory for elderly among rural Indian elderly population. Archives of Gerontology and Geriatrics, 55, 762-767.

Heo, S. D. (2015). The outcome of hearing screening in young children and adolescents. Journal of Speech \& Hearing Disorders, 24, 161-168.

Heo, S. D. (2016). Hearing threshold of children with hearing screening-passed in day care center and speech-language pathology clinic. Journal of Rehabilitation Welfare Engineering \& Assistive Technology, 11, 273-278.

Heo, S. D., Park, C. H., \& Song, B. S. (2017). Comparison of Smart Phone Application Based Hearing Screening and Hearing Handicap Inventory. Journal of Rehabilitation Welfare Engineering \& Assistive Technology, 10, 73-79.

Hong, B., \& Lee, J. (2002). Hearing threshold and hearing handicap of the elderly with presbycusis. Korean Journal of Communication Disorders, 7, 214233.

Kang, S. H., \& Yoon, S. Y. (2013). A study on the necessary income of the disabled and improvement of disability pension. Korean Social Security Studies, 29, 55-82.

Kim, S. H., \& Yeo, S. G. (2015). Presbycusis. Hanyang Medical Reviews, 35, 78-83.

Korea Internet \& Security Agency. (2015). 2015 Survey on the mobile internet usage executive summary. http://isis.kisa.or.kr/board/?pageId=060200 \&bbsId=3\&itemId $=809$

Korea Ministry of Health and Welfare. (2014). More than $45 \%$ of 60 s, visit to outpatient department due to hearing problem. http://www.mohw.go.kr/ front_new/al/sal0301vw.jsp?PAR_MENU_ID=04\&MENU_ID=0403\& CONT_SEQ=304381\&page $=1$

Korea Ministry of the Interior. (2016). Age-related demographics based on resident registration. http://rcps.egov.go.kr:8081/ageStat.do?command= month

Korean Statistical Information Service. (2016). Number of registered disabled depending on the age, type of disability, and gender in nationwide. http:// kosis.kr/statHtml/statHtml.do?orgId=117\&tblId=DT_11761_N003\&conn_ path=I2

Ku, H., \& Kim, J. (2000). Test-retest reliability of the Korean Hearing Handicap Inventory for the Elderly (KHHIE). Korean Journal of Communication Disorders, 5, 1-22.

Lee, D. (2016, August 25). Hearing loss is the cause of mental illnesses such as dementia and depression, should enhance the using of hearing aids. Busan Ilbo. http://news20.busan.com/controller/newsController.jsp?newsId= 


\section{7}

Lee, J. H. (2011). Cochlear implantation in the elderly. Journal of the Korean Medical Association, 54, 925-934.

Lichtenstein, M. J., \& Hazuda, H. P. (1998). Cross-cultural adaptation of the Hearing Handicap Inventory for the Elderly-Screening version (HHIE-S) for use with Spanish-Speaking Mexican Americans. Journal of the American Geriatrics Society, 46, 492-498.

Lin, F. R., Metter, E. J., O’Brien, R. J., Resnick, S. M., Zonderman, A. B., \& Ferrucci, L. (2011). Hearing loss and incident dementia. Archives of Neurolo$g y, 68,214-220$.

Liu, X. Y., Han, Y., \& Yang, S. M. (2016). A hearing self-reported survey in people over 80 years of age in China by hearing handicap inventory for the elderly: complete version vs screening version. Acta Oto-Laryngologica, 136, 1242-1247.

Martin, F. N., \& Clark, J. G. (2015). Introduction to audiology (12th ed.). Seoul: Pakhaksa.

Monzani, D., Genovese, E., Palma, S., Rovatti, V., Borgonzoni, M., \& Martini, A. (2007). Measuring the psychosocial consequences of hearing loss in a working adult population: focus on validity and reliability of the Italian translation of the hearing handicap inventory. Acta Otorhinolaryngologica Italica, 27, 186-191.

Öberg, M. (2016). Validation of the Swedish Hearing Handicap Inventory for the Elderly (screening version) and evaluation of its effect in hearing aid rehabilitation. Trends in Hearing, 20. http://dx.doi.org/10.1177/23312165 16639234

Oh, S. H., \& Heo, S. D. (2016). Results of hearing screening in senior high school students. Journal of Rehabilitation Welfare Engineering \& Assistive Technology, 10, 1-7.

Park, S. (2016, July 1). Smart phone penetration rate. Digital Times. http:// www.dt.co.kr/contents.html?article_no $=2016070102100151780001$

Pratt, S. (2016). Assessing and treating of auditory complaints in blast-ex- posed military veterans. Proceedings of the 4th International Conference on Korea Speech-Language \& Hearing Association and International Conference on Communication Disorders and Related Sciences, Gwangju, Korea.

Project Team for Audiology Study Group. (2014). Ling 6 Sound Test app. https: //play.google.com/store/apps/details?id=appinventor.ai_powerjoguh.Ling6 \&hl=ko

Project Team for Audiology Study Group. (2015). Pure tone screening app. https:/play.google.com/store/apps/details?id=com.chanho.puretone\&hl=ko Schmiedt, R. A. (2010). The physiology of cochlear presbycusis. In S. Gordon-Salant et al. (Eds.), The aging auditory system (pp. 9-38). New York, NY: Springer.

Schuknecht, H. F. (1993). Pathology of the ear (2nd ed.). In: Martin, F. N., Clark, J. G. (2015). Introduction to audiology (12th ed.). Boston: Pearson.

Sogebi, O. A., \& Mabifah, T. O. (2015). Validation of hearing handicap inventory for the elderly questionnaire among elderly subjects in Sagamu, Nigeria. Nigerian Postgraduate Medical Journal, 22, 228-232.

Statistics Korea. (2016). Life expectancy of infant in 2015. http://kostat.go.kr

Tomioka, K., Ikeda, H., Hanaie, K., Morikawa, M., Iwamoto, J., Okamoto, N., ... \& Kurumatani, N. (2013). The Hearing Handicap Inventory for ElderlyScreening (HHIE-S) versus a single question: reliability, validity, and relations with quality of life measures in the elderly community, Japan. Quality of Life Research, 22(5), 1151-1159.

Ventry, I. M., \& Weinstein, B. E. (1982). The hearing handicap inventory for the elderly: a new tool. Ear and Hearing, 3, 128-134.

Weinstein, B. E., Rasheedy, D., Taha, H. M., \& Fatouh, F. N. (2015). Crosscultural adaptation of an Arabic version of the 10-item hearing handicap inventory. International Journal of Audiology, 54, 341-346.

Woo, J. I., Lee, J. H., Yoo, K. Y., Hong, J. P., Kim, C. Y., Kim, Y. I., \& Lee, K. W. (1997). Prevalence of dementia in the elderly residents of a rural community in Korea. Journal of Korean Neuropsychiatric Association, 36, 92-102. 
Appendix 1. Hearing Handicap Inventory for Elderly (HHIE) 설문 문항

01. 듣기 힘들어서 전화 통화를 피한다.

02. 듣기 힘들어서 사람 만나면 부끄럽다.

03. 듣기 힘들어서 모임을 피한다.

04. 듣기 힘들어서 짜증이 난다.

05. 듣기 힘들어서 가족과의 대화에도 어려움을 느낀다.

06. 듣기 힘들어서 모임에서 곤란을 느낀 경험이 있다.

07. 듣기 힘들어 하는 내가 '바보'같이 느껴진다.

08. 상대가 작은 말소리를 하면 듣기 어렵다.

09. 듣기 곤란한 정도가 장애라고 생각한다.

10. 이웃이나 친지 방문 시 듣기 문제로 곤란을 느겼다.

11. 실수할까봐 모임 참석을 피한다.

12. 듣기 위해 긴장한다.

13. 실수할까봐 이웃 친지 방문을 피한다.

14. 듣는 문제로 가족이나 타인과 말다툼을 한다.

15. TV 시청, 라디오 청취에 어려움이 있다.

16. 듣기 힘들어서 장보기를 줄인다.

17. 말소리가 잘 들리지 않아 화가 난다.

18. 들으려고 긴장하기 싫어서 혼자 있고 싶다.

19. 가족들과 대화를 피하기도 한다.

20. 듣는 문제로 성격도 변하고, 사회생활도 달라졌다.

21. 가족 회식에서 잘 듣지 못해 오해가 생기기도 했다.

22. 잘 들리지 않아 우울하다.

23. TV나 라디오는 이제 멀리한다.

24. 친구와 만남을 피하지 않으나 불편함을 느낀다.

25. 친구들과 대화에서 소외감을 느낀다. 


\section{국문초록}

\section{Hearing Handicap Inventory for Elderly (HHIE)로 확인한 노인성 난청 실태 허승덕}

대구대학교 재활과학대학 언어치료학과

배경 및 목적: 이 연구는수정한 우리말 Hearing Handicap Inventory for Elderly (HHIE)를 스마트폰 기반으로 조사하여 도시 및 도농 지역 노인성 난청 실태를 확인하고자 한다. 방법: 연구 대상은 도시 지역 거주 65세 이상 92명으로 하였다. 이들은 나이에 따라 65-69세 를 1군, 70-79세를 2군, 80 세 이상을 3 군으로 각각 분류하였다. 설문은 증폭기 사용자 10 명을 제외한 82명을 조사하였고, 응답은 79 명이 완성하였다. 내적타당도는 Cronbach's alpha coefficient로 $(\alpha=.918)$, 난청 의심 기준은 18 점 이상으로 하였다. 난청 실태는 증폭기 사용 자와 모든 설문을 응답한 89명을 대상으로 분석하였다(one-way ANOVA, Pearson 상관분석). 결과: HHIE로 확인한 유소견자 비율은 1 군부터 $16.7 \%, 25.5 \%, 45 \%$ 로 집단 간 차이가 있었고( $p=.003)$, 나이가 들수록 유의하게 높아졌다 $(r=.392, p=.01)$. 증폭기 사용자를 포 함한 난청 실태는 같은 순서로, $22.2 \%, 37.3 \%, 60 \%$ 로 집단 간차이가 있었고 $(p=.004)$, 나이가 들수록 유의하게 증가하였다 $(r=.319, p=.01)$. 논의 및 결론: 노인성 난청은 나이가 들어가면서 급격하게 증가하고 있으며, HHIE는 청력검사와 마찬가지로 유용한 청각선별 도구로 사용할수 있다.

핵심어: 노인성 난청, 노화, 청력, HHI, Hearing Handicap Inventory, HHE

\section{참고문헌}

강성호, 윤상용(2013). 장애인 필요소득 추정과장애연금 개선 방안. 사회보장연구, 29, 55-82.

구호림, 김진숙(2000). 한국 노인성 난청의 청각장애지수 (KHHIE)에 관한 검사. 언어청각장애연구, 5, 1-22

국가통계포털(2016). 등록장애인수-전국 연령별, 장애유형별, 성별. http://kosis.kr/statHtml/statHtml.do?orgId=117\&tblId=DT_11761_N003\&conn_ path=I2

김상훈, 여승근(2015). 노인성난청. 한양의대학술지, 35, 78-83.

보건복지부(2014). 난청 진료환자, 60대 이상 고령층이 $45 \%$ 차지. http://www.mohw.go.kr/front_new/al/sal0301vw.jpp?PAR_MENU_ID =04\& MENU_ID $=0403 \& C O N T \_S E Q=304381 \&$ page $=1$

오승하, 허승덕(2016). 고등학생 청각선별 결과. 재활복지공학회논문지, 10, 1-7.

우종인, 이정희, 유근영, 홍진표, 김창엽, 김용익, 이강욱(1997). 한국의 한 농촌 지역에 거주하는 노인에서의 치매의 유병률. 신경정신의학, 36, 92-102. 이준호(2011). 노인 난청 환자에서의 와우이식술. 대한의사협회지, 54, 925-934.

청각학연구회(2014). Ling 6 Sound Test app. https://play.google.com/store/apps/details?id = appinventor.ai_powerjoguh.Ling6\&hl=ko 청각학연구회(2015). 순음청각선별(pure tone screening). https://play.google.com/store/apps/details?id = com.chanho.puretone\&hl=ko 통계청(2016). 2015 출생아 기대 수명. http://kostat.go.kr 한국인터넷진흥원(2015). 2015 모바일인터넷이용실태조사. http://isis.kisa.or.kr/board/?pageId= 060200\&bbsId = 3\&itemId = 809 행정자치부(2016). 주민등록 연령별 인구통계.http://rcps.egov.go.kr:8081/ageStat.do?command= month 허승덕(2015). 유소아 및 청소년 청각선별 결과. 언어치료연구, 24, 161-168.

허승덕(2016). 청각선별을 통과한 주간 보호와 언어재활 서비스 수혜 소아의 가청역치. 재활복지공학회논문지, 10, 273-278.

허승덕, 박찬호, 송병섭(2017). 스마트 폰 애플리케이션 기반 청각선별과 설문 청각선별의 비교. 재활복지공학회논문지, 11, 73-79.

홍빛나, 이정학(2002). 노인성난청의 청력역치와 청각장애지수. 언어청각장애연구, 7, 214-233.

Frederick N. Martin, John Greer Clark (2015). 청각학개론 12판(허승덕 역). 서울: 박학사. 